Published in final edited form as:

ACS Appl Mater Interfaces. 2016 May 4; 8(17): 10761-10766. doi:10.1021/acsami.6b01765.

\title{
Visible-Light-Activated Bactericidal Functions of Carbon "Quantum” Dots
}

\author{
Mohammed J. Meziani ${ }^{\dagger, \|}$, Xiuli Dong ${ }^{\ddagger, \|}$, Lu Zhu ${ }^{\S, \|}$, Les P. Jones ${ }^{\Uparrow}$, Gregory E. LeCroy ${ }^{\dagger}$, Fan \\ Yang $^{\dagger}$, Shengyuan Wang ${ }^{\ddagger}$, Ping Wang ${ }^{\dagger}$, Yiping Zhao ${ }^{*}, \perp$, Liju Yang ${ }^{*}, \ddagger$, Ralph A. Tripp ${ }^{*}$, , and \\ Ya-Ping Sun ${ }^{*} \dagger$ \\ tDepartment of Chemistry and Laboratory for Emerging Materials and Technology Clemson \\ University, Clemson, South Carolina 29634, United States \\ ‡Department of Pharmaceutical Sciences, Biomanufacturing Research Institute and Technology \\ Enterprise, North Carolina Central University, Durham, North Carolina 27707, United States \\ $\S$ College of Engineering, University of Georgia, Athens, Georgia 30602, United States \\ IDepartment of Infectious Diseases, University of Georgia, Athens, Georgia 30602, United States \\ ${ }^{\perp}$ Department of Physics and Astronomy and Nanoscale Science and Engineering Center, \\ University of Georgia, Athens, Georgia 30602, United States
}

\begin{abstract}
Carbon dots, generally defined as small carbon nanoparticles with various surface passivation schemes, have emerged as a new class of quantum-dot-like nanomaterials, with their optical properties and photocatalytic functions resembling those typically found in conventional nanoscale semiconductors. In this work, carbon dots were evaluated for their photoinduced bactericidal functions, with the results suggesting that the dots were highly effective in bacteria-killing with visible-light illumination. In fact, the inhibition effect could be observed even simply under ambient room lighting conditions. Mechanistic implications of the results are discussed and so are opportunities in the further development of carbon dots into a new class of effective visible/natural light-responsible bactericidal agents for a variety of bacteria control applications.
\end{abstract}

\section{Graphical abstract}

\footnotetext{
*Corresponding Authors: zhaoy@physast.uga.edu.; lyang@ nccu.edu.; ratripp@uga.edu.; syaping@clemson.edu. Authors contributed equally.

Supporting Information

The Supporting Information is available free of charge on the ACS Publications website at DOI: 10.1021/acsami.6b01765.

Available experimental results for the visible-light-activated bactericidal effect of carbon dots on two other bacteria (Gram-positive and Gram-negative) (PDF)

Notes

The authors declare no competing financial interest.
} 


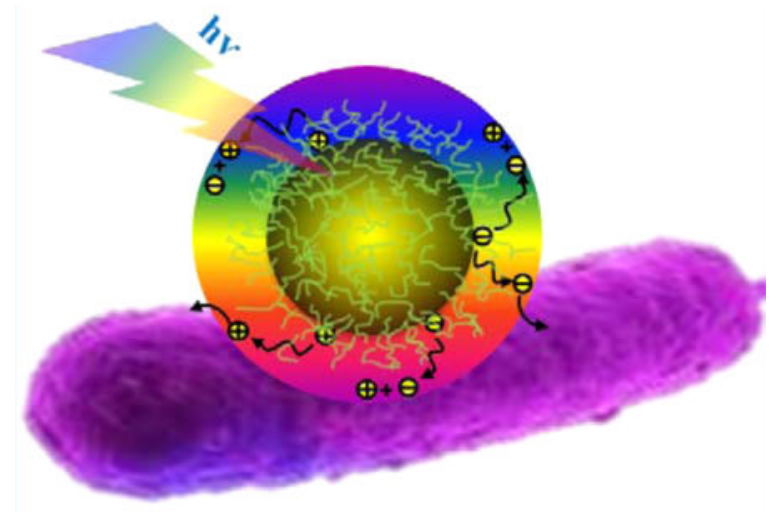

\section{Keywords}

carbon dots; bactericidal functions; light activation; photodynamic effect; E. coli; colloidal $\mathrm{TiO}_{2}$

\section{INTRODUCTION}

Bacterial infections present a major healthcare challenge, especially with the increasing bacterial resistance to antibiotics, ${ }^{1,2}$ demanding the development of alternative antimicrobial strategies. Among the most effective alternatives is the use of photoactivated antimicrobial nanomaterials and nanotechnology, for which the recent rapid advances offer some unique opportunities. Nanoscale semiconductors have been a popular choice for their photoinduced redox properties and associated bactericidal functions. For example, colloidal $\mathrm{TiO}_{2}$ has been widely employed as a photocatalyst for antibacterial and general disinfection purposes. ${ }^{3}$ However, a significant limitation with $\mathrm{TiO}_{2}$ nanostructures is the large band gap $(3.2 \mathrm{eV})$, requiring $\mathrm{UV}$ activation. Therefore, there has been much effort on the modification of $\mathrm{TiO}_{2}$ via doping or coupling with dyes or narrower-band-gap materials to extend photoexcitation into the visible spectrum. ${ }^{3-6}$ Alternative semiconductors and other nanomaterials for visiblelight-responsive antibacterial activities have been pursued. ${ }^{7-9}$ Visible-light activation considerably broadens the reach of the photochemical antimicrobial agents, potentially enabling their uses under solar irradiation or natural-light exposure to inhibit the growth of pathogens and other infectious agents. Our focus has been on exploring the newly developed carbon "quantum" dots, or more appropriately called carbon dots for their lack of classical quantum confinement behavior, ${ }^{10}$ for their visible-light-activated bactericidal functions.

Carbon dots (Figure 1),${ }^{10}$ generally defined as small carbon nanoparticles with various surface passivation schemes, ${ }^{11}$ have emerged as a new class of quantum-dot-like nanomaterials, with their optical properties and photocatalytic functions resembling those found in conventional nanoscale semiconductors. ${ }^{11-17}$ For example, in addition to their bright and colorful fluorescence emissions, carbon dots have been demonstrated as effective visible-light photocatalysts for oxidation and reduction reactions. ${ }^{17,18}$ The same photoinduced redox processes responsible for the photocatalytic activities should make carbon dots excellent candidates as antibacterial agents, for which a major advantage is the broad and strong optical absorption of carbon dots over the visible spectral region, extending 
into the near-IR. Here we report the experimental confirmation on the bactericidal functions of photoexcited carbon dots. 2,2' -(Ethylenedioxy)bis(ethylamine) (EDA) carbon dots were selected for being compact in structure and well-characterized in a previously reported study. ${ }^{19}$ The evaluation experiments were performed under household LED lighting or ambient laboratory light conditions, and the carbon dots inhibited Escherichia coli cells in all of the experimental settings. These results and their mechanistic implications are discussed.

\section{RESULTS AND DISCUSSION}

Carbon nanoparticles as precursors to carbon dots were obtained from the commercially supplied carbon nanopowder sample by following an established protocol including the refluxing of the as-supplied sample in an aqueous nitric acid solution, dialysis, centrifuging to retain the supernatant, and then drying to recover the carbon nanoparticles. The nanoparticles were surface-functionalized with EDA under amidation reaction conditions to yield EDA carbon dots. ${ }^{19,20}$ Briefly, the carbon nanoparticles were refluxed in neat thionyl chloride, followed by the removal of excess thionyl chloride, and then the sample was mixed well with carefully dried EDA. The mixture was heated and stirred at $120^{\circ} \mathrm{C}$ with nitrogen protection in the experimental setup designed for reactions under refluxing conditions. The reaction mixture was dispersed in water and centrifuged to retain the supernatant as the assynthesized sample, which was further purified by removing residual small molecular species including free EDA in dialysis against deionized water to obtain EDA carbon dots in an aqueous solution. The solution appeared optically transparent (Figure 2), stable without any precipitation over an extended period of time (many months). The solubility and solution stability may be expected for these dots, being small carbon nanoparticles with the surface well-functionalized by hydrophilic molecules (Figure 1). According to results from atomic force microscopy (AFM) and transmission electron microscopy (TEM) characterization, the EDA carbon dots were on the order of $5 \mathrm{~nm}$ diameter (Figure 3).

The optical absorption of carbon dots is due to a $\pi$-plasmon transition in the carbon nanoparticle core, with a broad absorption spectrum covering most of the visible region (Figure 2). The carbon dots in aqueous solution are brightly fluorescent, with the emission colors dependent on the excitation wavelengths (Figure 2), which along with the broad fluorescence spectra suggests a distribution of emissive excited states. It is known in the literature that the fluorescence emissions of carbon dots could be quenched effectively with either electron donors or acceptors, supporting the notion that the redox characteristics in the photoexcited states of carbon dots are responsible for their observed photocatalytic activities. ${ }^{11,21,22}$ The same characteristics were exploited in this study for their visiblelight-activated bactericidal functions.

E. coli (K12) cells were used in the experiments to evaluate the antibacterial activities of photoexcited carbon dots, with the cell growth measurements based on the optical density (OD) at $600 \mathrm{~nm}$ (OD600) and/or the viable cell number determined by the plating method. Experimentally, the E. coli cells were inoculated in a 12 -well plate at $0.2 \mathrm{OD} / \mathrm{mL}$ per well, treated with the EDA carbon dots of different concentrations, and exposed to ambient light for an hour in a safety cabinet. Then, the plate was incubated for $21 \mathrm{~h}$, followed by the 
measurement of OD600. As shown in Figure 4, the results clearly suggest that there were substantial effects of the EDA carbon dots with light exposure on the E. coli cells. In the literature, there was a report on some antibacterial activities of the carbon dots obtained from carbonization of glucose and poly(ethylenimine), with the dots quaternized with benzyl bromide before bacteria experiments. ${ }^{23}$ While no deliberate light exposure was mentioned in that report, the ambient experimental conditions could have contributed to the reported observations.

Similarly, the $E$. coli cells in aqueous suspension were mixed with an aqueous solution of EDA carbon dots, and the resulting mixture containing $\sim 10^{7}$ colony-forming units per milliliter (CFU/mL) E. coli was incubated for $30 \mathrm{~min}$ at room temperature under visiblelight illumination ( $12 \mathrm{~V}, 36 \mathrm{~W}$ bulb in a light box) or in the dark as the control. Then, the growth of $E$. coli cells after treatment with and without light exposure was monitored. Shown in Figure 5 are the growth curves of $E$. coli in a brain heart infusion medium posttreatment with EDA carbon dots, along with the control (untreated cells), based on OD measurements at $595 \mathrm{~nm}$ (OD595). The treated cells exhibited much prolonged lag phases (7-8 h) compared to the control, indicating that the EDA carbon dots inhibited/inactivated the growth of bacterial cells. The effect was somewhat more pronounced (the lag phase was longer by $1 \mathrm{~h}$ ) when the treatment included exposure to visible light (Figure 5), but the light versus dark inhibition difference was not as obvious as that shown in Figure 4 (for which the experiments were performed in different laboratories at different times). Therefore, to address the inconsistency issue at the quantitative level for the OD measurement method, separate experiments with the same parameters and conditions were performed for the inhibition effect probed by the more quantitative method of determining the viable cell numbers post-treatment.

Again the samples of $E$. coli with and without (control) carbon dots were treated in the light box or in the dark for $30 \mathrm{~min}$. The viable cell numbers in the treated samples were determined, and according to the results (Figure 6), the EDA carbon dots treatment coupled with visible-light illumination was obviously effective for bacteria killing, with about 4 logs of $E$. coli cells killed. Compared to the results shown in Figure 4, the bacteria-killing effect seemed more dramatic in these experiments. A significant contributing factor might be the use of a lamp instead of ambient light for the photoexcitation of carbon dots, although more systematic and quantitative experiments are needed in further investigation. Nevertheless, the results are all consistent in terms of confirming the visible-light-activated bactericidal functions of EDA carbon dots.

A different experimental configuration was employed for further evaluation on the bactericidal activities of EDA carbon dots, in which the dots were plated on the trypticase soy agar (TSA) plates with bacteria cells during visible-light exposure. In a typical experiment, an E. coli (TOP10) suspension of $1.3 \times 10^{3} \mathrm{CFU} / \mathrm{mL}$ concentration was mixed with an aqueous solution of EDA carbon dots, and the mixture was spread onto the TSA plates. Upon exposure of the plates to visible light (Osram Sylvania LED A19 lamp, 10 $\mathrm{mW} / \mathrm{cm}^{2}$ ) for up to $6 \mathrm{~h}$, there were obvious differences between the treated plate and controls (Figure 7), again suggesting a substantial bactericidal effect of carbon dots with visible-light illumination. The plates were read for CFU counts, and according to the results, 
the photoexcited carbon dots were very effective in inactivating the growth of bacteria cells (Figure 7).

The results presented above, which were obtained in different laboratories of the participating research groups under various experimental settings, provide consistent and unambiguous evidence for the highly effective bactericidal functions of carbon dots under visible-light illumination, including even the common household lighting conditions.

Mechanistically, carbon dots have been demonstrated for photodynamic effects on cancer cells, ${ }^{24,25}$ and similar effects on bacterial cells might be a logical extension. The current mechanistic framework for the known optical properties of carbon dots is such that upon photoexcitation there are efficient charge separations for the formation of radical anions and cations (electrons and holes in a somewhat different description), which are "trapped" at various passivated surface sites. The radiative recombination of redox pairs is responsible for the observed fluorescence emissions, with their associated emissive excited states of lifetimes on the order of a few nanoseconds. ${ }^{26-28}$ The redox species and emissive excited states could, in principle, be responsible for the observed bactericidal functions. However, in the fluorescence decay measurements, the rise time for the fluorescence was generally within the instrumental response function ( $1 \mathrm{~ns}$ or less), suggesting rather fast radiative recombination and short lifetimes of the radical-ion species. Therefore, the emissive excited states are more likely responsible for the photodynamic effects.

There have been no reports in the literature that explicitly describe the apparently effective bactericidal functions of photoexcited carbon dots. As related, there have been a few studies of using "graphene quantum dots" as photodynamic agents. ${ }^{9,} 29,30$ In the study by Ristic et al., ${ }^{9}$ antibacterial activities were observed with $470 \mathrm{~nm}$ light irradiation of the graphene quantum dots obtained from the electrochemical method. Those dots are essentially graphitic nanoparticles, which share optical properties similar to those of the precursor carbon nanoparticles for carbon dots. ${ }^{16}$ However, the surface passivation of the carbon nanoparticles in carbon dots (or similarly in surface-passivated graphene quantum dots) substantially improves the optical properties, as is often reflected in the much enhanced fluorescence emissions. ${ }^{11,16,17}$ Because the emissive excited states are likely responsible for the observed bactericidal functions, carbon dots with the more effective surface passivation and correspondingly more fluorescence are likely more desirable in serving as visible-light-activated bactericidal agents for a variety of bacteria control applications. In further investigations, steady-state and kinetic studies that correlate the optical properties of carbon dots, such as different fluorescence quantum yields and average lifetimes at various emission colors, with their antibacterial performance will be pursued.

\section{CONCLUSION}

The results obtained in this work, while somewhat more qualitative than quantitative in some of the experiments, demonstrate unambiguously that carbon dots can readily be activated by visible light (or even under ambient room lighting conditions) for significant bactericidal functions. The light sensitivity of carbon dots is apparently rather high to the degree that would require unusually stringent experimental conditions for the dark control, an issue (such as that in Figure 5) to be examined more closely and quantitatively in further 
investigations, although the determination of viable cell numbers (Figure 6) should remain a more favorable method in general. Also investigated will be the issues important to the quantification of the light-activated biocidal functions, including their correlations with the properties of carbon dots in various structural and surface configurations.

\section{EXPERIMENTAL SECTION}

\section{Materials}

Carbon nanopowder (purity $>99 \%$ ) and $2,2^{\prime}$-(ethylenedioxy)bis(ethylamine) (EDA) were purchased from Sigma-Aldrich. Thionyl chloride (>99\%) was obtained from Alfa Aesar and nitric acid from VWR. Dialysis membrane tubing of various cutoff molecular weights was supplied by Spectrum Laboratories. Water was deionized and purified by being passed through a Labconco WaterPros water purification system.

\section{Measurement}

Baxter Megafuge (model 2630), Eppendorf (model 5417 R), and Beckman-Coulter (Optima L90K with a type $90 \mathrm{Ti}$ fixed-angle rotor) ultracentrifuges were used for centrifugation at various $g$ values. Optical absorption spectra were recorded on a Shimadzu UB2501-PC spectrophotometer. Fluorescence spectra were measured on a Jobin-Yvon emission spectrometer equipped with a $450 \mathrm{~W}$ xenon excitation source, Gemini-180 excitation and Tirax-550 emission monochromators, and a Hamamatsu R928P PMT photon-counting detector operated at $950 \mathrm{~V}$. AFM images were acquired in the acoustic AC mode on a Molecular Imaging PicoPlus AFM system equipped with a multipurpose scanner and a NanoWorld point probe NCH sensor. Height profile analysis was assisted by using the SjPIP software distributed by Image Metrology. TEM images were obtained on a Hitachi H9500 high-resolution TEM system.

\section{Carbon Dots}

For carbon nanoparticles as the precursors for carbon dots, an as-supplied carbon nanopowder sample $(1 \mathrm{~g})$ was refluxed in an aqueous nitric acid solution $(5 \mathrm{M}, 90 \mathrm{~mL})$ for $48 \mathrm{~h}$. The reaction mixture was cooled to ambient temperature and then dialyzed against fresh water for up to 3 days. The postdialysis mixture was centrifuged at $1000 \mathrm{~g}$ to retain the supernatant, followed by the removal of water to obtain the desired carbon nanoparticle sample.

In the synthesis of EDA carbon dots using a previously reported procedure,,${ }^{19}$ the carbon nanoparticle sample obtained from the processing above was refluxed in neat thionyl chloride for $12 \mathrm{~h}$, followed by the removal of excess thionyl chloride under nitrogen. The post-treatment carbon nanoparticle sample $(50 \mathrm{mg})$ was mixed well with carefully dried EDA (500 mg) in a flask, heated to $120^{\circ} \mathrm{C}$, and stirred vigorously under nitrogen protection for 3 days. The reaction mixture was cooled to ambient temperature, dispersed in water, and then centrifuged at $20000 \mathrm{~g}$ to retain the dark supernatant as an aqueous solution of the assynthesized sample. The solution was dialyzed in membrane tubing (cutoff molecular weight 250) against fresh water to remove free EDA and other impurities to obtain the EDA carbon dots in aqueous solution. For microscopy characterization only, the EDA carbon dots 
were very lightly coated with gold by visible-light irradiation of the solution with $\mathrm{HAuCl}_{4}$ for a few minutes. ${ }^{31}$

\section{Light-Activated Bactericidal Functions}

For one set of experiments, E. coli (K12) cells were cultured in fresh nutrient broth overnight, and OD600 values of these cultures were measured and then standardized to 1 $\mathrm{OD} / \mathrm{mL}$. The bacteria suspension at $0.2 \mathrm{OD} / \mathrm{mL}$ per well was inoculated in a 12 -well plate. Four treatment groups with different concentrations of carbon dots at $0.25,0.50,1$, and $2 \mu \mathrm{M}$ were exposed under light in a safety cabinet for $T=0,15,30$, and $60 \mathrm{~min}$, respectively. Then, the 12 -well plate was incubated at $37{ }^{\circ} \mathrm{C}$ for $21 \mathrm{~h}$. The OD600 value of each well was recorded, and the readings were standardized to that of the $T=0$ control plate.

For another set of experiments, fresh grown E. coli (K12) cells in nutrient broth (Fisher Scientific, Pittsburgh, PA) were washed three times and then resuspended in deionized water. With the use of 96-well plates, to a well was added a bacteria—carbon dots mixture (150 $\mu \mathrm{L}$ ), in which the bacteria concentration was fixed at $1.0 \times 10^{6} \mathrm{CFU} / \mathrm{mL}$ and the concentration of carbon dots was varied (triplicate for each concentration). The plates were either exposed to visible light ( $12 \mathrm{~V}, 36 \mathrm{~W}$ light bulb) or kept in the dark for $30 \mathrm{~min}$. The solutions in the wells were then transferred to $1.5 \mathrm{~mL}$ centrifuge tubes, followed by centrifugation at $8000 \mathrm{rpm}$ for $5 \mathrm{~min}$. The supernatants were discarded, and the bacterial pellets were washed twice with deionized water. The cells were resuspended in $500 \mu \mathrm{L}$ of nutrient broth, with $150 \mu \mathrm{L}$ distributed into the wells of a 96-well plate for incubation at $37^{\circ} \mathrm{C}$. The growth of carbon-dot-treated bacterial cells and untreated cells (as controls) were monitored by measuring the OD595 values at various time points on a Spectra Max M5 spectrophotometer (Molecular Devices, LLC, Sunnyvale, CA).

For the viable cell number determination by using the traditional plating method, the suspended $E$. coli cells post-treatment with various concentrations of carbon dots were centrifuged and washed twice. The cells were resuspended in phosphate-buffered saline (PBS), and a series of dilutions were made with PBS. Aliquots of $100 \mu \mathrm{L}$ appropriate dilutions were surface-plated on Luria-Bertani agar plates (Fisher Scientific, Pittsburgh, PA), and the plates were incubated at $37^{\circ} \mathrm{C}$ for $24 \mathrm{~h}$. The number of colonies was counted, and the viable cell numbers of the treated samples and controls were calculated in colonyforming units per milliliter.

In the use of the direct plating method for evaluation of the light-activated bactericidal functions, an E. coli (TOP10) stock culture was activated in fresh tryptic soy broth at $37^{\circ} \mathrm{C}$ overnight. The bacteria culture $(1 \mathrm{~mL})$ was washed twice by a combination of centrifuging at $4000 \mathrm{rpm}$ and resuspending in sterile PBS. The resulting cell suspension was 10-fold serially diluted in PBS. For detection of the cell concentration, aliquots of $100 \mu \mathrm{L}$ dilutions were plated onto TSA plates and incubated at $37{ }^{\circ} \mathrm{C}$ overnight before counting. Separately, the $E$. coli suspension $(50 \mu \mathrm{L})$ at a concentration of $1.3 \times 10^{3} \mathrm{CFU} / \mathrm{mL}$ was mixed with aqueous solution of EDA carbon dots $(50 \mu \mathrm{L})$ at a concentration of $1 \mathrm{mg} / \mathrm{mL}$. The mixture was then plated onto TSA plates, which were exposed to LED light (Osram Sylvania LED A19 lamp, $\sim 10 \mathrm{~mW} / \mathrm{cm}^{2}$ ) for up to $6 \mathrm{~h}$, along with the dark control (without light exposure), light control (without carbon dots), and negative control (without carbon dots and light). The 
carbon-dot-treated plates with light exposure and all control plates were incubated at $37^{\circ} \mathrm{C}$ for $24 \mathrm{~h}$ before counting to determine the viable cell numbers.

All experiments were performed in triplicate or more. Statistical analysis of the experimental results was performed using the Student $t$ test, with $P<0.05$ considered as a significant difference.

\section{Supplementary Material}

Refer to Web version on PubMed Central for supplementary material.

\section{Acknowledgments}

The authors thank Dr. Rene Alvarez and Dr. Kranti Yemmireddy for their help throughout the project. Financial support from NIH Grant R15GM114752 (to L.Y. and Y.-P.S.) and Agriculture and Food Research Initiative Grant 2011-68003-30012 by the USDA National Institute of Food and Agriculture (to L.Z. and Y.Z.) is gratefully acknowledged. M.J.M. was a visiting faculty on leave from Department of Natural Sciences, Northwest Missouri State University, with support provided by the NSF and South Carolina Space Grant Consortium.

\section{References}

1. Rodriguez-Rojas A, Rodriguez-Beltran J, Couce A, Blazquez J. Antibiotics and Antibiotic Resistance: A Bitter Fight Against Evolution. Int J Med Microbiol. 2013; 303:293-297. [PubMed: 23517688]

2. Laxminarayan R, Duse A, Wattal C, Zaidi AKM, Wertheim HF, Sumpradit N, Vlieghe E, Hara GL, Gould IM, Goossens H, Greko S, So AD, Bigdeli M, Tomson G, Woodhouse W, Ombaka E, Peralta AQ, Qamar FN, Mir F, Kariuki S, Bhutta ZA, Coates A, Bergstrom R, Wright GD, Brown ED, Cars O. Antibiotic Resistance - The Need for Global Solutions. Lancet Infect Dis. 2013; 13:1057-1098. [PubMed: 24252483]

3. Liou JW, Chang HH. Bactericidal Effects and Mechanisms of Visible Light-Responsive Titanium Dioxide Photocatalysts on Pathogenic Bacteria. Arch Immunol Ther Exp. 2012; 60:267-275.

4. Cheng CL, Sun DS, Chu WC, Tseng YH, Ho HC, Wang JB, Chung PH, Chen JH, Tsai PJ, Lin NT, Yu MS, Chang HH. The Effects of the Bacterial Interaction with Visible-Light Responsive Titania Photocatalyst on the Bactericidal Performance. J Biomed Sci. 2009; 16:7. [PubMed: 19272171]

5. Chen YL, Chen YS, Chan H, Tseng YH, Yang SR, Tsai HY, Liu HY, Sun DS, Chang HH. The Use of Nanoscale Visible Light-Responsive Photocatalyst TiO2-Pt for the Elimination of Soil-Borne Pathogens. PLoS One. 2012; 7:e31212. [PubMed: 22384003]

6. Anehosur GV, Kulkarni RD, Naik MG, Nadiger RK. Synthesis and Determination of Antimicrobial Activity of Visible Light Activated $\mathrm{TiO}_{2}$ Nanoparticles with Polymethyl Methacrylate Denture Base Resin Against Staphylococcus Aureus. J Gerontol Geriat Res. 2012; 11000103.

7. Foster HA, Ditta IB, Varghese S, Steele A. Photocatalytic Disinfection Using Titanium Dioxide: Spectrum and Mechanism of Antimicrobial Activity. Appl Microbiol Biotechnol. 2011; 90:18471868. [PubMed: 21523480]

8. Applerot G, Lipovsky A, Dror R, Perkas N, Nitzan Y, Lubart R, Gedanken A. Enhanced Antibacterial Activity of Nanocrystalline ZnO Due to Increased ROS-Mediated Cell Injury. Adv Funct Mater. 2009; 19:842-852.

9. Ristic BZ, Milenkovic MM, Dakic IR, Todorovic-Markovic BM, Milosavljevic MS, Budimir MD, Paunovic VG, Dramicanin MD, Markovic ZM, Trajkovic VS. Photodynamic Antibacterial Effect of Graphene Quantum Dots. Biomaterials. 2014; 35:4428-4435. [PubMed: 24612819]

10. Sun Y-P, Zhou B, Lin Y, Wang W, Fernando KAS, Pathak P, Meziani MJ, Harruff BA, Wang X, Wang H, Luo PG, Yang H, Kose ME, Chen B, Veca LM, Xie S-Y. Quantum-Sized Carbon Dots for Bright and Colorful Photoluminescence. J Am Chem Soc. 2006; 128:7756-7757. [PubMed: 16771487] 
11. Luo PG, Sonkar SK, Yang S-T, Yang F, Yang L, Broglie JJ, Liu Y, Sun Y-P. Carbon-Based Quantum Dots for Fluorescence Imaging of Cells and Tissues. RSC Adv. 2014; 4:10791-10807.

12. Wang Y, Hu A. Carbon Quantum Dots: Synthesis, Properties and Applications. J Mater Chem C. 2014; 2:6921-6939.

13. Lim SY, Shen W, Gao Z. Carbon Quantum Dots and Their Applications. Chem Soc Rev. 2015; 44:362-381. [PubMed: 25316556]

14. Miao P, Han K, Tang Y, Wang B, Lin T, Cheng W. Recent Advances in Carbon Nanodots: Synthesis, Properties and Biomedical Applications. Nanoscale. 2015; 7:1586-1595. [PubMed: 25510876]

15. Zhao A, Chen Z, Zhao C, Gao N, Ren J, Qu X. Recent Advances in Bioapplications of Carbon Dots. Carbon. 2015; 85:309-327.

16. Cao L, Meziani MJ, Sahu S, Sun Y-P. Photoluminescent Properties of Graphene versus Other Carbon Nanomaterials. Acc Chem Res. 2013; 46:171-180. [PubMed: 23092181]

17. Fernando KAS, Sahu S, Liu Y, Lewis WK, Guliants EA, Jafariyan A, Wang P, Bunker CE, Sun YP. Carbon Quantum Dots and Applications in Photocatalytic Energy Conversion. ACS Appl Mater Interfaces. 2015; 7:8363-8376. [PubMed: 25845394]

18. Cao L, Sahu S, Anilkumar P, Bunker CE, Xu J, Fernando KAS, Wang P, Guliants EA, Tackett KN II, Sun Y-P. Carbon Nanoparticles as Visible-Light Photocatalysts for Efficient $\mathrm{CO}_{2}$ Conversion and Beyond. J Am Chem Soc. 2011; 133:4754-4757. [PubMed: 21401091]

19. LeCroy GE, Sonkar SK, Yang F, Veca LM, Wang P, Tackett KN II, Yu J-J, Vasile E, Qian H, Liu Y, Luo PG, Sun Y-P. Toward Structurally Defined Carbon Dots as Ultracompact Fluorescent Probes. ACS Nano. 2014; 8:4522-4529. [PubMed: 24702526]

20. Wang Y, Anilkumar P, Cao L, Liu J-H, Luo PG, Tackett KN, Sahu S, Wang P, Wang X, Sun Y-P. Carbon Dots of Different Composition and Surface Functionalization: Cytotoxicity Issues Relevant to Fluorescence Cell Imaging. Exp Biol Med. 2011; 236:1231-1238.

21. Wang X, Cao L, Lu F, Meziani MJ, Li H, Qi G, Zhou B, Harruff BA, Sun YP, Kermarrec F. Photoinduced Electron Transfer with Carbon Dots. Chem Commun. 2009:3774-3776.

22. Zhang H, Huang H, Ming H, Li H, Zhang L, Liu Y, Kang Z. Carbon Quantum Dots $/ \mathrm{Ag}_{3} \mathrm{PO}_{4}$ Complex Photocatalysts with Enhanced Photocatalytic Activity and Stability Under Visible Light. J Mater Chem. 2012; 22:10501-10506.

23. Dou Q, Fang X, Jiang S, Chee PL, Lee T-C, Loh XJ. Multi-Functional Fluorescent Carbon Dots with Antibacterial and Gene Delivery Properties. RSC Adv. 2015; 5:46817-46822.

24. Kleinauskas A, Rocha S, Sahu S, Sun Y-P, Juzenas P. Carbon-Core Silver-Shell Nanodots as Sensitizers for Phototherapy and Radiotherapy. Nanotechnology. 2013; 24:325103. [PubMed: 23868054]

25. Juzenas P, Kleinauskas A, Luo PG, Sun Y-P. Photo-activatable Carbon Nanodots for Cancer Therapy. Appl Phys Lett. 2013; 103:063701.

26. Wang X, Cao L, Yang S-T, Lu F, Meziani MJ, Tian L, Sun KW, Bloodgood MA, Sun Y-P. Bandgap-Like Strong Fluorescence in Functionalized Carbon Nanoparticles. Angew Chem, Int Ed. 2010; 49:5310-5314.

27. Strauss V, Margraf JT, Dolle C, Butz B, Nacken TJ, Walter J, Bauer W, Peukert W, Spiecker E, Clark T, Guldi DM. Carbon Nanodots: Toward a Comprehensive Understanding of Their Photoluminescence. J Am Chem Soc. 2014; 136:17308-17316. [PubMed: 25372278]

28. Wang L, Zhu S-J, Wang H-Y, Qu S-N, Zhang Y-L, Zhang J-H, Chen Q-D, Xu H-L, Han W, Yang B, Sun H-B. Common Origin of Green Luminescence in Carbon Nanodots and Graphene Quantum Dots. ACS Nano. 2014; 8:2541-2547. [PubMed: 24517361]

29. Markovic ZM, Ristic BZ, Arsikin KM, Klisic DG, Harhaji-Trajkovic LM, Todorovic-Markovic BM, Kepic DP, Kravic-Stevovic TK, Jovanovic SP, Milenkovic MM, Milivojevic DD, Bumbasirevic VZ, Dramicanin MD, Trajkovic VS. Graphene Quantum Dots as AutophagyInducing Photodynamic Agents. Biomaterials. 2012; 33:7084-7092. [PubMed: 22795854]

30. Ge J, Lan M, Zhou B, Liu W, Guo L, Wang H, Jia Q, Niu G, Huang X, Zhou H, Meng X, Wang P, Lee C-S, Zhang W, Han X. A Graphene Quantum Dot Photodynamic Therapy Agent with High Singlet Oxygen Generation. Nat Commun. 2014; 5:4596. [PubMed: 25105845] 
31. Xu J, Sahu S, Cao L, Bunker CE, Peng G, Liu Y, Fernando KAS, Wang P, Guliants EA, Meziani MJ, Qian H, Sun Y-P. Efficient Fluorescence Quenching in Carbon Dots by Surface-Doped Metals - Disruption of Excited State Redox Processes and Mechanistic Implications. Langmuir. 2012; 28:16141-16147. [PubMed: 23088301] 


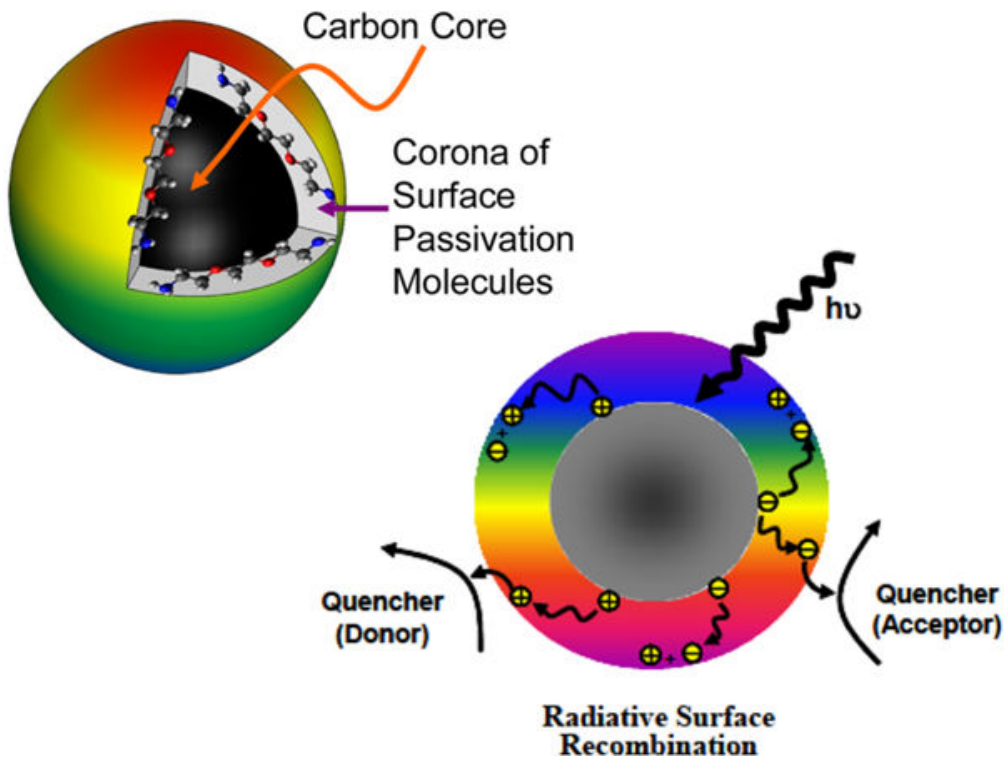

Figure 1.

Cartoon illustrations of (left) a carbon dot, with a small carbon nanoparticle core and the surface functionalization molecules forming a soft shell, and (right) the photoexcited-state species and processes, with the rainbow color showing fluorescence from the dot surface. 

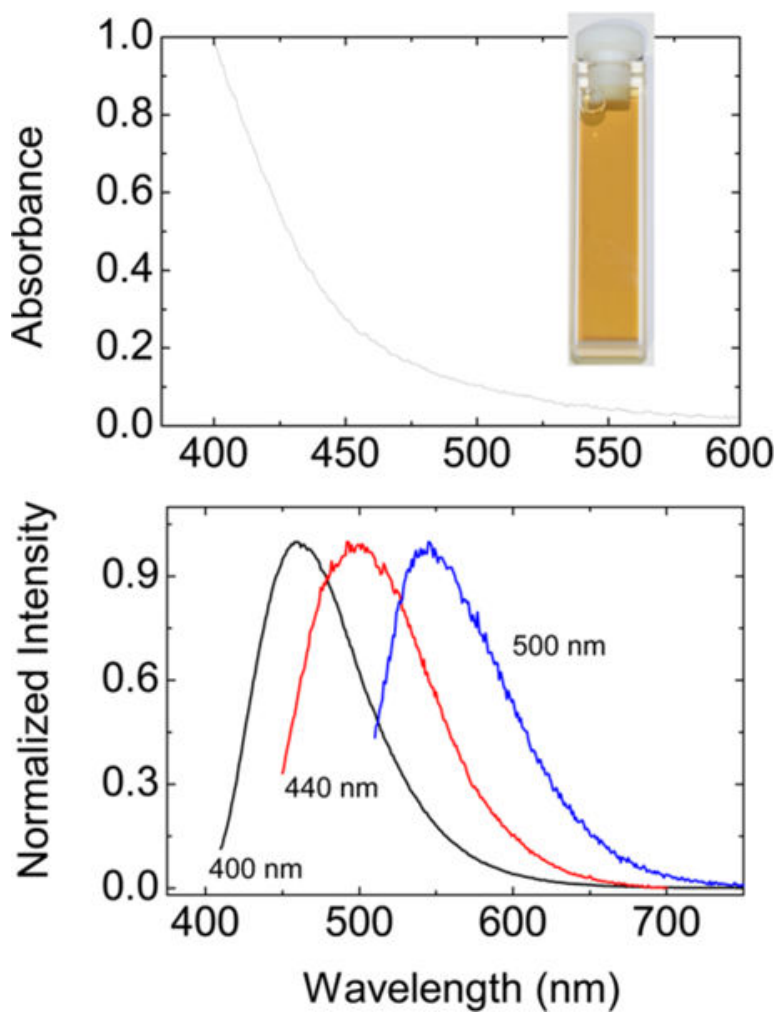

Figure 2.

Top: Absorption spectrum of the EDA carbon dots in an aqueous solution (photograph in the inset). Bottom: Fluorescence spectra of the EDA carbon dots in an aqueous solution excited at the indicated wavelengths. 


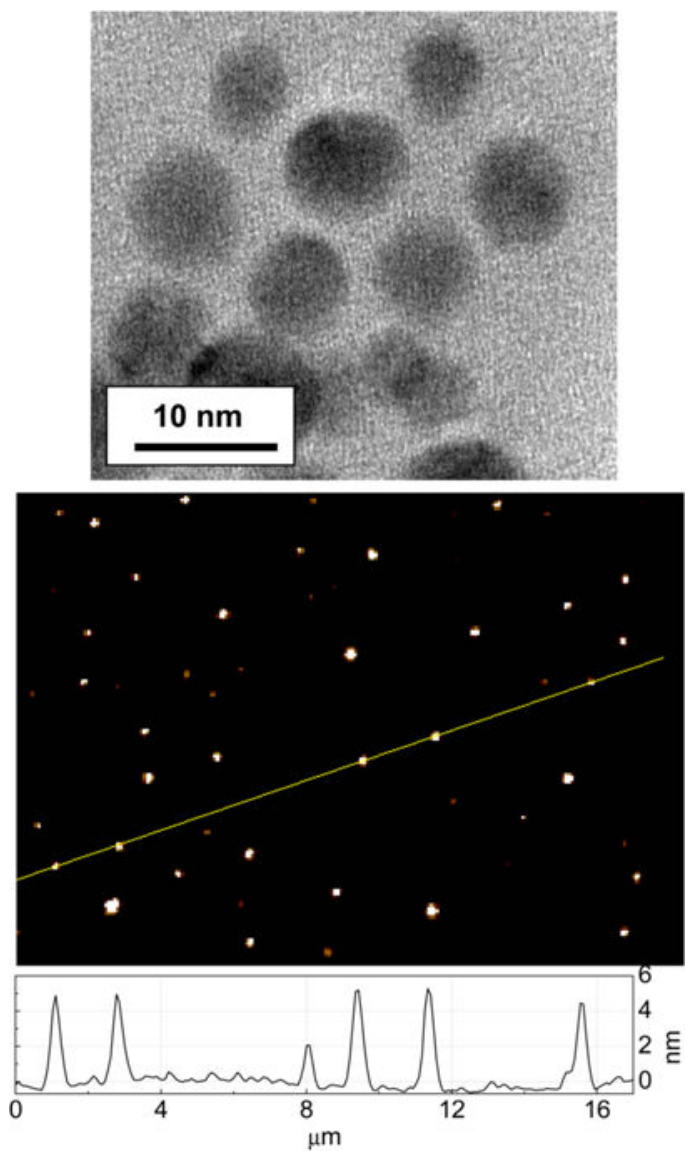

Figure 3.

TEM (top) and AFM (bottom) images of the EDA carbon dots on commercial TEM grid and mica, respectively. 


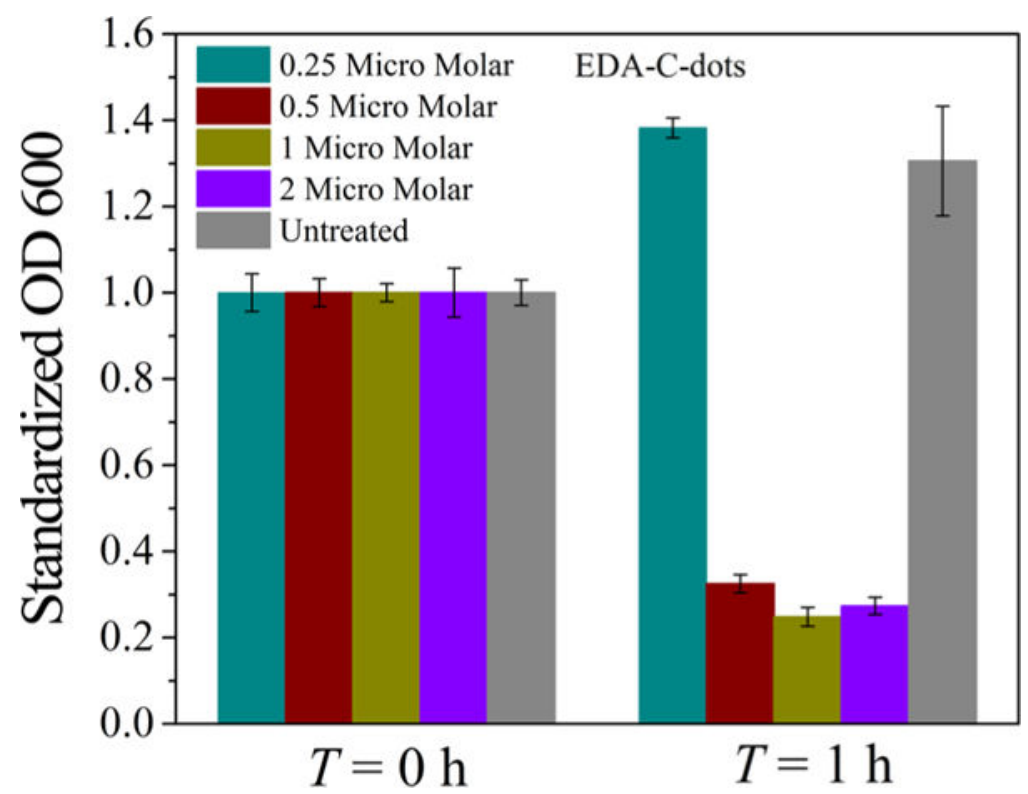

Figure 4.

Photoinduced bacteria inactivation measured by OD600 for the EDA carbon dots (presented as mean \pm standard deviation of quadruplicate experimental results). 


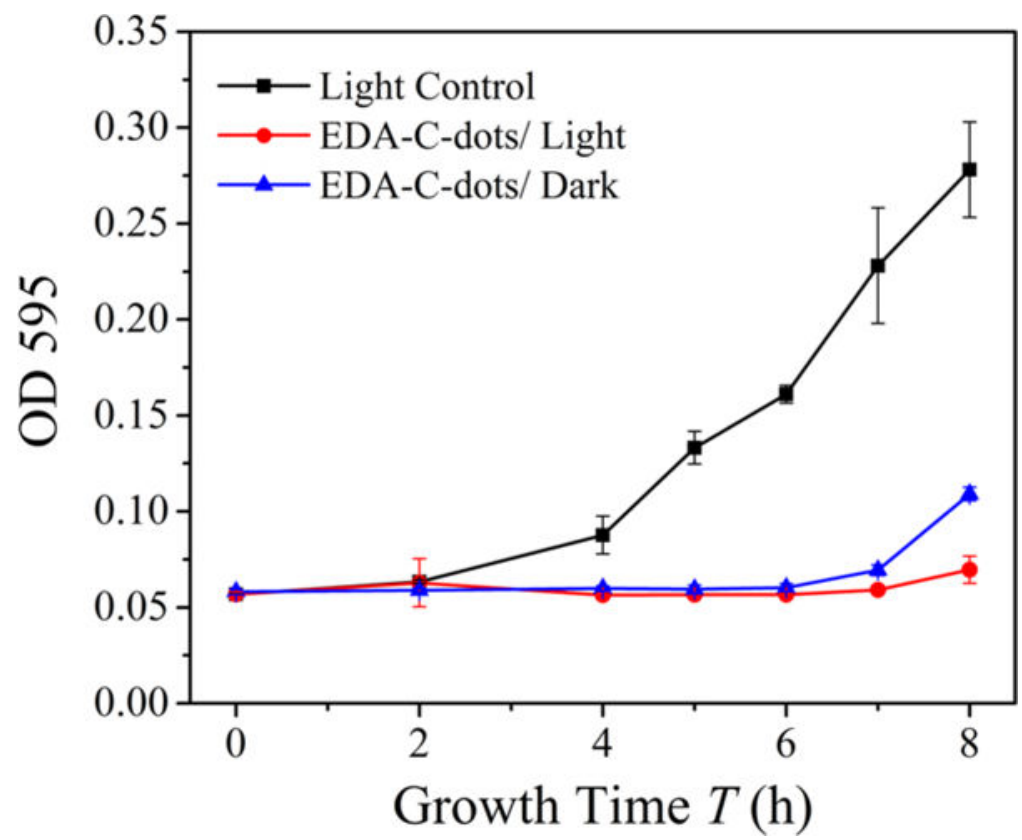

Figure 5.

Growth curves of $E$. coli cells post-treatment with the EDA carbon dots for 30 min with or without light, in terms of measuring the OD595 values. 


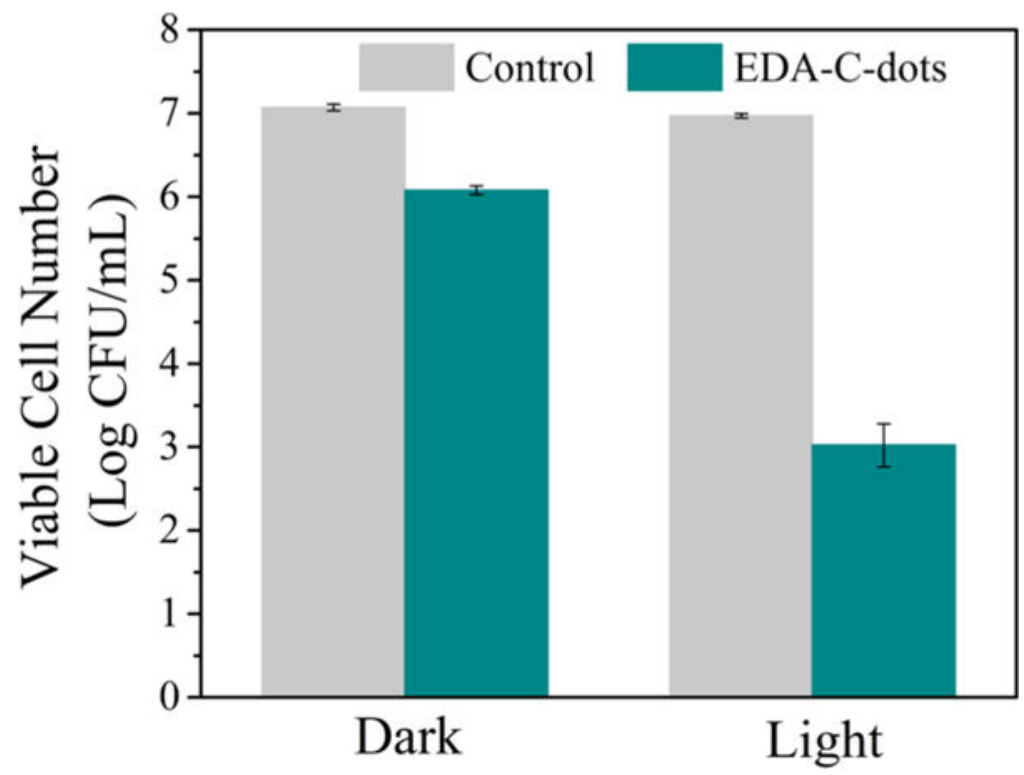

Figure 6.

Reductions in the viable cell number after $E$. coli cells were treated with the EDA carbon dots for 30 min with or without light (presented as mean \pm standard deviation of triplicate experimental results, and the data were also analyzed using the Student $t$ test with $P<0.05$ as a significant difference; see also Supporting Information). 

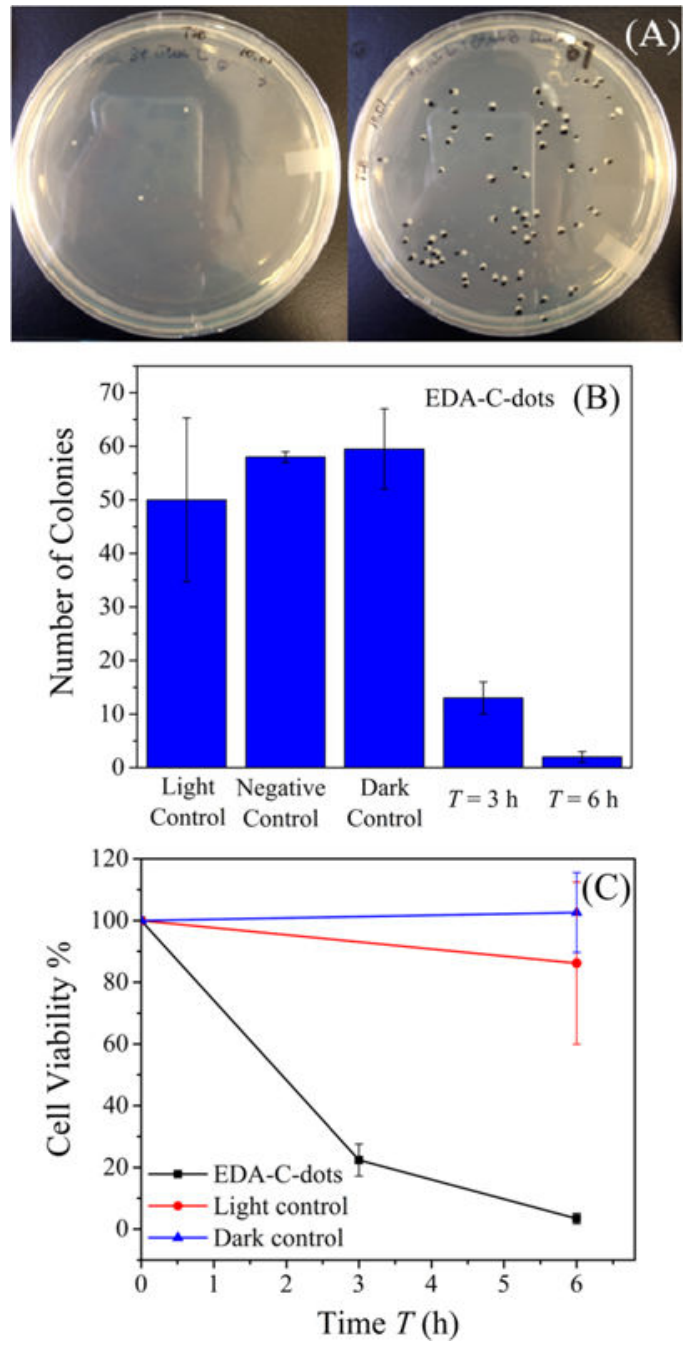

Figure 7.

Photoinduced bacteria inactivation by the EDA carbon dots: (A) photographs showing colonies on TSA plates (left, 6 h treatment; right, dark control); (B) E. coli colony numbers; (C) cell viability ratio. The carbon dots were presented in the dark control. 